\title{
Arqueología medieval en la Comarca Sur de Sevilla: el término histórico de Morón de la Frontera
}

\author{
Manuel Vera Reina *
}

\section{Introducción}

Uno de los principales problemas con que tropieza cualquier estudio sobre las etapas antigua y medieval de la comarca Sur de Sevilla es la falta de tradición arqueológica lo que supone, habida cuenta de la escasez de documentación escrita previa a la fase de frontera con el reino nasrí, un vacío informativo casi completo que obliga al historiador a partir prácticamente de cero.

En este sentido, el repaso bibliográfico a las actuaciones arqueológicas medievales en esta zona, aunque tenga como objetivo primordial establecer cuáles fueron las principales líneas de trabajo en los últimos siglos y sus aportaciones más destacadas, no puede limitarse, para su exacta comprensión, a este período sino que debe extenderse, aunque sea sucintamente, a las actividades arqueológicas que se desarrollaron sobre otras etapas de nuestra historia; de este modo contaremos con una idea contextualizada del tema. Por otro lado, será interesante cotejar las conclusiones de este análisis con las directrices que en el ámbito nacional seguía la arqueología andalusí. Con ello obtendremos un conocimiento aproximado de la difusión de las nuevas propuestas metodológicas en áreas, como ésta, carentes y alejadas de los centros de investigación más importantes.

Se trata, quede claro, de examinar el funcionamiento de la arqueología medieval en un territorio que no posee conjuntos monumentales de entidad, capaces por sí solos de llamar la atención de los investigadores y que tampoco cuenta con centros sólidos de investigaciones u organismos administrativos que canalicen los esfuerzos culturales.

Varias circunstancias específicas deben tenerse en cuenta para comprender correctamente el recorrido bibliográfico que pretendemos establecer. La primera, y quizás más general, se refiere al concepto mismo de arqueología. Como cualquier disciplina metodológica, la Arqueología se ha ido definiendo paulatinamente a lo largo del tiempo, de modo que los significados que hoy encierra son en ocasiones muy distintos $y$, a veces, hasta contradictorios con los que en otros momentos se le han asignado. Así, pues, daremos cabida aquí a una serie de trabajos que en un sentido riguroso no podrían incluirse en la actualidad dentro del campo estricto de la arqueología.

Otra de las características particulares a tener en cuentan dentro de este apartado es la extensión del término histórico de Morón que, sin entrar en discusiones geográficas (MORILLA, 1992 y 1994) que desbordarían los propósitos de este trabajo, comprendía un ámbito territorial que abarcaba los actuales municipios de Morón, Arahal, Montellano, Coripe, Puerto Serrano y un sector mínimo de la parte Sur de El Coronil (Fig I). Todo ello procura una extensión de 890,5 km²; lo que supone casi el

* Arqueólogo 
$7 \%$ de la superficie de la provincia. Constituye, pues, a escala espacial un muestreo bastante significativo. Por otro lado, también hemos de indicar que precisamente la amplitud del área a estudiar ha facilitado la dispersión de la información y una casi total descontextualización de la misma.

Otra cuestión particular a destacar es la diversidad de ámbitos geográficos que concurren en nuestra zona. Ello implica diferentes maneras de asentamiento, distintas estrategias productivas, etc. pero también supone tratamientos historiográficos diversos. Así, por ejemplo, la campiña rica y accesible ha tenido una continuidad bibliográfica mientras que la presierra más pobre y peor comunicada ha pasado prácticamente desapercibida para los investigadores.

Por otro lado, hemos de advertir que aquellos trabajos que se centren exclusivamente en los castillos de Morón o Cote como unidades arquitectónicas serán comentados muy brevemente y siempre en relación al panorama global de las actividades arqueológicas del momento ya que esos estudios serán publicados de manera independiente y monográfica en un libro de reciente aparición.

Aclaradas estas cuestiones previas pasemos, sin más demora, al análisis historiográfico de la arqueología medieval en nuestra región.

\section{Siglos XVII-XVIII}

El comienzo del repaso a las investigaciones medievales en este sector debe remontarse, como no podía ser de otra manera, a mediados del siglo XVII, concretamente a la figura de A. Bohorques (1994) y a la publicación de su Anales de Morón. En este libro se fijó, hasta prácticamente nuestros días, el conocimiento histórico sobre los períodos antiguo y medie- val de la ciudad y su término histórico. Buena prueba de lo que estamos refiriendo fueron las historias posteriores escritas por J. J. Janer y D. Zafra (1858) ', F. Collantes de Terán (1990), etc. que se limitaron a repetir, cuando no a resumir, sin juicio crítico alguno, los datos aportados por el erudito moronés.

La etapa andalusí, que es la que nos interesa, recibe en todos los trabajos anteriores a 1912 un tratamiento secundario ya que la falta de datos y el escaso interés que despertó en los historiadores locales imposibilitaba establecer un relato mínimamente coherente de cualquier suceso de aquella fase. Su estudio se resolvía, en la mayoría de los casos, en un par de páginas como máximo, donde se recogían informaciones inconexas sobre aspectos muy distintos. Estas informaciones desde A. Bohorques casi siempre hacen referencia a los siguientes temas: descripción de una lápida funeraria aparecida en el cerro de la Atalaya, disquisiciones en función del texto de al-Rāzī acerca del nombre de Morón y del lugar donde se situaba su capital y algunas apreciaciones sobre la Torre de Maraga Zamara, Morgazmara o de don Mendo.

No obstante, de estas noticias nos interesa destacar varias cuestiones: En primer lugar, la ubicación del cementerio musulmán en el cerro de la Atalaya basándose en la aparición de la lápida funeraria, de la que además comenta: "(...) es digno decir que en este cerro mismo, donde en aquel tiempo se enterró Zaide, se entierran hoy todos los moros que mueren en esta comarca, que aunque sea desde muchas leguas, traen a sus amigos a enterrar aquí. Deben de tener memoria de que es lugar señalado para esos por sus antiguos, o tiene algunas particularidades para su propósito. Pero después de que se ha sembrado de pan este sitio, lo han dejado (...)." (BOHORQUES, 1994, p. 21). Lógicamente, esta afirmación fue tomada de un documento anterior, posiblemente del libro de Bonilla ${ }^{2}$, ya que cuando

\footnotetext{
I De esta obra dice M. García en su estudio sobre la historiografía moronense: "En la parte segunda [del libro] se examina la historia de Morón desde su fundación hasta mediados del siglo XIX. Sin embargo, todo el buen hacer que suscita la parte primera se echa en falta en la segunda, al seguir literalmente los Anales de Bohorques Villalón". (GARCÍA FERNANDEZ, 1992. p. 56).

2 “A finales del siglo XVI o tal vez a inicios del siglo XVII Luis Gutiérrez Bonilla, cura beneficiario de San Miguel debió escribir una Historia de Morón que hoy permanece ilocalizada (...) parece que debió tratarse de una magnífica obra redactada en tres tomos de tamaño folio. En el primero se historiaban los hechos más sobresalientes de la villa desde el siglo XIII. En los dos restantes, en cambio, se ofrecía una copia de aquellos documentos más significativos de Morón que se custodiaban en el archivo municipal". (GARCíA FERNANDEZ, 1992, p. 53).
} 
nuestro autor redactaba su obra los moriscos habían sido expulsados de España y las gentes que aún permanecieran en aquella creencia bien se guardarían de manifestarla con una Inquisición en pleno auge. No obstante, la referencia escrita de que tras la conquista aquel lugar continuó, durante algunos siglos, empleándose como espacio cimenterial entre los musulmanes resulta de gran interés de cara a la posible ubicación de la maqbara andalusí. En segundo lugar, sitúa Movier -nombre que recibe Morón ${ }^{3}$ en la crónica de al-Rāzī que A. Bohorques leyó ${ }^{4}$ - en el Moguerejo apoyándose en ciertas similitudes fonéticas entre ambos nombres y en los estudios que al respecto llevó a cabo el Padre Martín de Roa (1617) y el castillo de Carpio lo identifica con el de Cote. En último lugar, reproduce algunas noticias de Bonilla acerca del castillo (BOHORQUES, 1994, p. 24) que constituyen, por el momento, las referencias topográficas más antiguas e interesantes sobre la ciudad islámica y de los siglos inmediatos a la conquista.

La amistad de nuestro autor con Rodrigo Caro generó un extenso epistolario entre ambos personajes. En él comentaban sobre distintas cuestiones de nuestro pasado histórico, se daban a conocer los últimos hallazgos arqueológicos aparecidos en la región, muchos de los cuales sólo son conocidos en la actualidad gracias a estas breves notas ${ }^{5}$, etc. También en esta correspondencia trataron algunas cuestiones acerca del pasado medieval de nuestra comarca aunque estos temas, dada la formación renacentista del erudito utrerano, le atraían bastante menos que los problemas referidos al mundo clásico, donde su aportación fue decisiva no sólo por la publicación de un buen número de vestigios epigráficos sino por su participación en debates sobre el origen de la ciudad, la identificación de ésta con el Arunci ${ }^{6}$ de Plinio, etc. En las disquisiciones sobre nuestro pasado romano también se vieron implicados ilustres historiadores de la época como A. Ortelius (1596) C. Florian de Ocampo (1578), S. de Covarrubias (1661), A. Barbosa (161 I), etc. Dado el escaso interés que despertaban en Rodrigo Caro las cuestiones medievales no nos debe extrañar que no tuviera problema en seguir las hipótesis de A. Bohorques acerca de la antigua capital de la circunscripción islámica, la cual sitúa en un despoblado entre el Coronil y Morón, en el camino que va a San Pablo de la Breña, a dos leguas de Morón, llamado "Movier" (CARO, 1634, II, fol. 184v).

En el siglo XVIII el panorama historiográfico cambia sustancialmente, tanto desde el punto de vista cuantitativo, ya que se produce una considerable disminución de los estudios que se ocupan de nuestro pasado más remoto, como desde el cualitativo pues la práctica totalidad de las nuevas publicaciones pueden incluirse dentro del estricto campo del coleccionismo. En efecto, las escasas obras que vieron la luz en este período son sucintas relaciones epigráficas o numismáticas que, junto a la reedición más cuidada de materiales ya divulgados, dan a conocer interesantes piezas inéditas. No obstante, estas obras a diferencia de las anteriores apenas transcienden el mero campo descriptivo y cuando lo hacen copian, sin el menor rubor, las teorías e hipótesis de los autores precedentes sin hacer intervenir en ellas las informaciones y datos que pudieran deducirse de

\footnotetext{
3 Acerca de las posibles causas fonéticas que motivaron la distorsión del nombre de Mauror en Movier véase el comentario de J. Pascual en: BOHORQUES; A. (1994). Anales de Morón. (p. 21 , nota. 49).

4 A. Bohorques consultó el manuscrito que se hallaba en la biblioteca de la Cartuja de Santa María de las Cuevas de Sevilla y que en la actualidad se encuentra desaparecido.

5 Así, por ejemplo, A. Bohorques informa a Rodrigo Caro de la localización de "una paloma de bronce con una hebilla muy grande en el lomo (...) una cabeza de mancebo de barro y en los carrillos dos pezones como de pechos de mujer (...)". Restos cuya única referencia de su existencia es esta breve nota. Biblioteca Colombina de Sevilla. Colección Santiago Montoto. Ms. 83-6-37. Doc. 42. fol. $80 \mathrm{v}$.

6 Acerca de la identificación de Arunci con Morón puede verse el apartado primero de PASCUAL, J. (I993): " El nombre latino y el origen de la ciudad de Morón" Desde la frontera, 6. Morón de la Frontera, pp. I-24.

7 A una errónea lectura de este autor de la obra de Plinio se debe la falsa identificación de Morón con Arunci que se ha mantenido hasta nuestros días.
} 
los nuevos vestigios. $\mathrm{Ni}$ que decir tiene que estos trabajos hacen referencia exclusiva a materiales clásicos, de modo que cualquier alusión o indicación sobre restos medievales, incluidos los visigodos, sencillamente no existen. Entre los principales autores de estos momentos hay que destacar a P. Gutiérrez Bravo (1765) y, a un nivel más global, a E. Florez (1773).

Varias cuestiones deben ser destacadas acerca de la elaboración historiográfica de este período. En primer lugar, la profesión clerical, como no podía ser de otro modo, de la mayoría de los autores. En segundo lugar, el hecho de que varias de estas obras fueron realizadas por expreso encargo de las autoridades eclesiásticas o civiles. En este sentido, no hay que olvidar que fue el propio Carlos I quién solicita a Florián de Ocampo la recogida de antigüedades romanas de España. Por último, el protagonismo del pasado clásico que constituyó el asunto principal y casi exclusivo de la mayoría de estos trabajos. El mundo romano es visto en este período con una aureola paradigmática en la que pueden apreciarse no solo las influencias renacentistas sino, y principalmente, los reflejos aún en pleno siglo XVII de los pensamientos de Gattinara sobre el Imperio Universal. Ideas que dominaron la política de los primeros Austrias, especialmente de Carlos I, y cuyas raíces más evidentes las constituyen el Sacro Imperio Germánico, según el sueño unitario de los gibelinos, y el Imperio Romano. No es raro, a tenor de estas circunstancias ideológicas, que los eruditos locales se afanen en establecer relaciones precisas entre los sucesos remotos acaecidos en sus localidades y la civilización clásica ${ }^{8}$. Con ello pretenden contribuir a la elaboración de un pasado glorioso de sus ciudades.

Es evidente que los vestigios de nuestro pasado islámico apenas tienen cabida en la redacción de estos trabajos. Un tribunal de la Inquisición en pleno auge y completamente asentado en la vida española ${ }^{9}$ y una política cada vez más hostigante hacia los moriscos que desemboca en su expulsión en los albores del siglo XVII lo que supone, como comenta J. Lynch (1975, II, pp. 60-7I) el colofón final de la obra de la "reconquista", desaconsejaban cualquier veleidad hacia ese campo. Lo musulmán es visto con ojos peyorativos como un hiatus en la historia de nuestro país que por fin había sido definitivamente cerrado ${ }^{10}$. No parecen esos siglos los tiempos más propicios para la producción de trabajos que tuvieran cómo objeto algún aspecto de la cultura material islámica. En este sentido, es interesante comprobar cómo la excepción a este desolado panorama la constituye la figura de A. Bohorques, quién precisamente se vió involucrado en un largo proceso judicial con el Santo Oficio acerca de su limpieza de sangre (BOHORQUES, 1994, p. VIII).

Los resultados de esta política fueron bastante contundentes ya que cuando se pretende recuperar los estudios arábigos en el siglo XVIII a raíz de la implantación de la Casa de los Borbones se han de "importar" del extranjero los responsables de dicho proyecto. Las iniciativas de retomar estos estudios se encuentran estrechamente apegadas a la figura real y a su ideario político-ilustrado. No olvidemos que una de las primeras obras que se traducen es "El libro de agricultura" de lbn 'Awwām, que el mismo rey apoya como una obra necesaria e imprescindible para mejor provecho de la agricultura de España (FERNANDEZ, 1991, pp. 8-9). También como resultado de la corriente ilustrada se produce un "distanciamiento" con la Iglesia que lleva a Godoy a plantearse la abolición de la Inquisición lo que, como reconocen todos los autores, favoreció el desarrollo paulatino de los estudios árabes. Ahora bien,

\footnotetext{
8 De este modo la fundación del castillo es atribuida a Aruns, hijo de Tarquino el Soberbio, el año 500 a. C. Otros autores afirman que este fue el campamento donde descansaron las tropas de Julio Cesar antes de la decisiva battalla de Munda contra los hijos de Pompeyo.

9 A. Domínguez (198I, cap. II) ha estudiado la normalización de esta institución en la vida cotidiana española y su papel en poblaciones como Morón.

10 De ello dan una idea muy justa las exhortaciones y discursos de Jaime Bleda domínico y miembro de la Inquisición de Valencia y de Juan de Ribera arzobispo de esta ciudad en los inicios del siglo XVII.
} 
esta corriente de pensamiento es francamente minoritaria $y$, por supuesto, no tiene ninguna repercusión en la comarca Sur donde la aristocracia y la burguesía seguían apegadas a los esquemas más pretéritos "', de modo que la cultura continuaba en aquellos años estando bajo la esfera exclusiva de la Iglesia y la Inquisición seguía teniendo su peso específico.

\section{Siglo XIX}

En la primera mitad del siglo XIX el panorama de las investigaciones apenas difiere del que veíamos con anterioridad, pero en la segunda mitad se van a producir importantes cambios cualitativos y cuantitativos en el ámbito de la arqueología de nuestra zona. Estas transformaciones que en un principio, y como es lógico suponer, apenas afectaron al campo específico de la cultura medieval fundamentaron, en cambio, las bases de las corrientes metodológicas y temáticas de la arqueología de nuestra zona hasta prácticamente nuestros días.

En estos momentos se producen los primeros estudios sobre la prehistoria de nuestra zona. Estas investigaciones se hallan claramente vinculadas a la expansión del pensamiento krausista en Sevilla, cuyo centro de difusión más destacado lo constituía la Universidad donde era Rector Federico de Castro, principal mentor de esta corriente, y personajes de la talla de Manuel Sales Ferrer también estrechamente relacionado con esta doctrina. Precisamente a dos de los alumnos formados en esta doctrina como F. Candau y Pizarro (1984) y C. Cañal y Migolla (1894 y 1896) se deben los primeros trabajos acerca de nuestra prehistoria. Son obras generales acerca de la provincia de Sevilla en las que se describen distintos aspectos de la cultura material de aquellos remotos períodos. En el caso concreto de nuestra zona se analizan los vestigios de varios yacimientos calcolíticos ubicados en el Pozo Amargo, Los Llanos, colada del Cañuelo, dehesa de
Párraga, etc. Por supuesto, estas obras hay que inscribirlas también dentro del despertar del mundo prehistórico que se estaba produciendo en aquellas fechas en España como atestiguan los trabajos de Fulgosio, Tubino, M. Gongora, etc. algunos de los cuales también analizaban, aunque más colateralmente, restos de nuestra zona. Despertar que no era más que un reflejo del interés que en aquellos años suscitaban estos estudios en Europa como demuestra el hecho de que la Gran Exposición de París de 187| dedique una importante sección a esta disciplina, a diferencia de la Exposición de Londres realizada veinte años antes.

Los estudios sobre la civilización material clásica continúan siendo el núcleo principal de las investigaciones arqueológicas en nuestra zona. En estos momentos se producen en este campo importantes cambios con respecto a las fases precedentes. Por supuesto, continúa la tradición anticuaria centrada en el riguroso inventario y descripción de materiales aunque en esta etapa la mayoría de las publicaciones no aportan hallazgos ni lecturas nuevas de las piezas sino que se limitan a repetir los comentarios ya conocidos. Pero lo más interesante, en lo que a esta etapa se refiere, fue el sugestivo debate que se abrió a raíz de las series epigráficas aparecidas acerca del municipium de Salpensa y de los Callenses Aeneanici. El primero es ubicado en el yacimiento de El Casar, antiguo Facialcázar, cortijo de Utrera, mientras que la república Callense es situada en el cortijo de Lumbrera-Moguerejo. Esta polémica ha provocado una extensa bibliografía en la que se vieron implicados ilustres filólogos-arqueólogos internacionales como Mommsen (1855) o Dirksen (1857) y nacionales como F. Fita ( 1887 ) quien dedicó un trabajo monográfico al tema.

Hasta aquí el repaso general a la arqueología de fines del XIX en la comarca. Abordamos ahora aquellos aspectos que atienden sólo a la civilización medieval. Durante este perío-

\footnotetext{
II F. Collantes de Terán (1990) ofrece al inicio del capítulo I| de la Parte Segunda unas breves pinceladas sobre el comportamiento de esta clase, la displicencia que le producía ciertos tipos de trabajos y el ahorro, la ostentación y el despilfarro superior incluso a las ganancias anuales que las rentas de la tierra le proporcionaban, etc. Todo ello es bastante esclarecedor al respecto de este tema.
} 
do se llevaron a cabo una serie de estudios sobre distintas cuestiones de nuestra cultura material medieval que resultan de extraordinario interés. Se trata de trabajos inscritos en las corrientes románticas o positivistas que, por desgracia, sólo ocasionalmente fueron publicados quedando la mayoría recluidos como manuscritos inéditos en los archivos personales de los autores e incluso algunos se encuentran en la actualidad desaparecidos.

Comenzaremos por la figura de F. Collantes de Terán y Caamaño. Este autor ejerció durante muchos años como diputado del Hospicio Municipal de Morón. Esta vinculación con la ciudad le llevó a desarrollar una profusa actividad investigadora que culminó en la redacción de una Historia de Morón con la que podemos decir que se cierra el ciclo historiográfico decimonónico comenzado a principios de aquel siglo por los científicos locales J.J. Janer y D. de Zafra. La obra, que ha permanecido inédita hasta hace pocos años, apenas tiene interés para nuestro asunto ya que las noticias históricas anteriores al siglo XVI son literalmente copiadas de la obra de A. Bohorques.

Sin embargo, el autor introduce al final del libro una sugestiva "Addenda" (COLLANTES DE TERÁN Y CAAMAÑO, 1990, pp. 207-210) dedicada a los Morones Figueredos sobre la que merece la pena detenerse un instante. Según este apartado, ellos habitaban en Morón antes de la invasión musulmana que describe como una sucesión de asaltos y luchas cruentas hasta el punto que "los españoles que no habían muerto o caído prisioneros se retiraron en una heroica salida al país montañoso de la Alpujarra, con objeto de vivir independientes." (p. 207), dejando a un lado las similitudes finales de este texto con la crónica de al-Maqqarī (GAYANGOS, 1964, I. p. 179. trad. p. 163), lo que nos importa destacar es que esta familia "creyó más conveniente permanecer en sus hogares, pactando con el jefe de los invasores pagar cierto tributo en señal de vasallaje" (COLLANTES DE TERÁN Y CAAMAÑO, 1990, p. 207). De este modo permanecieron en el actual cerro del Castillo hasta la conquista de los castellanos en 124I. En esos años habían crecido hasta constituir un núcleo poblacional muy numeroso que tuvo un papel destacado en la toma de la ciudad pues "tratarán de aprovechar la ocasión favorable que se le presentaba de sacudir el pasado yugo de los opresores" (p. 207). Desconocemos de donde pudo extraer esta información ya que aunque él afirma tomarla de los historiadores, lo cierto es que las crónicas e historias generales y locales anteriores nada dicen acerca de este tema.

Estos datos, la manera concreta en que son expuestos y su inclusión al final de la obra como un capítulo anexo posterior parecen una aportación postrera a la polémica suscitada en aquellos años acerca del papel de los mozárabes -no hay que olvidar que precisamente durante la redacción del libro apareció la obra que defiende más abiertamente el protagonismo de las comunidades cristianas en la configuración de la civilización andalusí (SIMONET, I897)y de la continuidad de lo hispánico en los siglos de la ocupación musulmana.

Este sentimiento de lo hispano fue un debate extensible a casi todos los intelectuales de finales del siglo pasado constituyendo uno de los temas principales del momento como queda reflejado, por ejemplo, en la Generación del 98. No obstante, lo que realmente se esconde detrás de esta afirmación "patria" no es más que el sentimiento de un pueblo que ve liquidar su poder colonial y que ha quedado completamente fuera del reparto del mundo. Así, dado el limitado papel internacional al que ha sido relegado, en vez de abrazar las teorías difusionistas que legitimarán su inferencia en otros países se vuelve sobre sí mismo y apoya teorías nacionales que ayudan a enmascarar la displicente situación.

La figura de los Morones Figueredos asegura en esta comarca la persistencia poblacional y religiosa desde época hispanorromana hasta la conquista cristiana. En otras palabras, lo que realmente garantiza o salva la existencia de esta familia a lo largo de estos siglos es la permanencia de lo hispano, la continuidad de un elemento propio e inalterable a las acciones extranjeras. F. Collantes de Terán con la elaboración de estos personajes participa y toma posición en el debate que, todavía de una 
manera incipiente, se estaba enunciando en aquellos momentos acerca de la esencia de nuestra historia y de la definición de sus componentes históricos o metahistóricos. Esta polémica en el campo del medievalismo encontrará bastante eco y en ella se implicarán personajes de la talla de Claudio Sánchez Albornoz, Menéndez Pidal, etc.

Pero lo que realmente nos interesa resaltar de la labor investigadora del erudito sevillano fue su proyecto de elaborar una historia global del ámbito conocido como la "Banda Morisca". Lamentablemente, este trabajo quedó inconcluso como consecuencia de su temprana muerte en 1895. Desconocemos, por tanto, los términos exactos en los que quedarían incluidos los análisis de los restos materiales que de esta etapa aún se mantenían en la región aunque pensamos que no deberían ser meramente accesorios habida cuenta de su interés por estos temas. No olvidemos que él fue el fundador de la Revista Arqueológica Sevillana y dirigió y promovió la publicación del Nuevo método de clasificación de las monedas autónomas de España de A. Delgado. No obstante, su "interés arqueológico" se dirigía exclusivamente a los restos arquitectónicos más importantes de la época de frontera; esto es, los castillos y las torres de vigilancia. En este sentido, podemos considerar de una manera no muy rigurosa este proyecto como el precedente remoto de la fructífera serie de trabajos que desde mediados del siglo $X X$ se vienen realizando en nuestra comarca sobre las edificaciones de frontera. Por último, señalar que la tarea de recopilación documental que realizó en los archivos locales como el de Morón sirvió de base para los estudios que años después llevó a cabo su nieto F. Collantes de Terán Delorme sobre este mismo asunto.

Directamente relacionado con el Proyecto de F. Collantes de Terán y Caamaño, como evidencia el que dicho autor pretendiera incluirlo en su libro como un apéndice final, se encuentra el estudio que en 1880 estaba realizando el arquitecto sevillano M. Gómez Imaz con el título de Historia de Morón bajo la dominación francesa. El título puede llevar a engaño ya que este trabajo se centraba en la evolución monumental y artística del castillo desde su construcción hasta la etapa de ocupación francesa. No sabemos si llegó a concluirlo o en qué términos fue redactado, ya que falta en las copias originales del libro de F. Collantes de Terán, de modo que en la actualidad el manuscrito se encuentra perdido.

En estos mismos años el arqueólogo J. Bonsor hizo varias incursiones en el campo de la cultura material medieval que, por desgracia, han pasado prácticamente desapercibidas en el conjunto de su obra. Dejando a un lado sus excavaciones en el alcázar de Arriba de Carmona donde buscó infructuosamente los tesoros del rey D. Pedro, o en la necrópolis romano-visigoda de Cañada Honda en El Gandul, lo que nos interesa destacar por lo que a nuestra zona se refiere es su obra inédita Les itineraires de l'invasion musulmana en Andalousie. Fouilles et tresors ${ }^{12}$. Como su título indica este trabajo se sitúa plenamente en la corriente romántica de la arqueología entendida como coleccionismo y exploración. La publicación en la segunda mitad del siglo XIX de un número importante de traducciones de fuentes árabes que tenían como tema central los acontecimientos de la conquista y los sucesos que acaecieron inmediatamente después, ofrecieron a Bonsor un volumen importante de datos geográficos relacionados con estos episodios históricos, que le permitió trasladar al medievalismo el debate filológico-arqueológico que desde hacía bastantes décadas se venía realizando en el campo de los estudios clásicos sobre las obras de Plinio, Estrabón y otros geógrafos romanos.

Las obras musulmanas de las que se valió para realizar su trabajo fueron primordialmente las de R. Dozy (|864 y |88|), la traducción de Ibn 'Abd al-Hakam (JONES, I858) y la de Al-Idrīsī (SAAVEDRA, |88I). La preferencia por las obras de arabistas europeos frente a los estudios y traducciones de la escuela his-

12 El manuscrito se halla en el Archivo General de Andalucía. Sección J. Bonsor. Leg. 7, p. 12. 
pana de la segunda mitad del siglo XIX (MANZANARES, 1972) puede explicarse por su origen y formación. No debemos olvidar que era inglés pero que su formación fue, debido a su madre, principalmente francesa hasta el punto que éste era el idioma habitual en el cual escribía. Su formación como medievalista era bastante desigual como indica el hecho de que su vasta biblioteca sólo contara con unos cuantos libros dedicados monográficamente a este período. No obstante, su relación con distinguidos arabistas del momento como P. de Gayangos, con quién sostuvo un interesante epistolario, palió algo esta laguna. Su imagen sobre el mundo musulmán no era muy positiva y eso queda reflejado a lo largo del manuscrito. Así, por ejemplo, Ṭāriq y Mūsā son tratados literalmente como sanguinarios y las tropas de invasión que desembarcaron con el general berébere difundía el terror a su paso ya que "(...)se alimentaban con la carne de sus prisioneros" (p.I I). La civilización andalusí tampoco era algo que le llamara la atención pues consideraba, como era común en su época, que la arqueología era una disciplina reservada a los estudios de prehistoria y mundo romano. Prueba de ello lo encontramos en su archivo personal donde con el título de Notas de cosas ajenas a la arqueología ${ }^{13}$ se incluyen unos papeles donde se recogían noticias que, según consta en el subtítulo, trataban de Historia, invasión árabes, notas varias sobre descubrimientos visigodos, árabes, etc.

La parte referente a nuestra área tiene un papel secundario en el conjunto de la obra. Se aprecia que apenas conocía la realidad arqueológica del término, ya que mientras en zonas como Arcos, Gibraltar y, sobre todo, Carmona se detiene en el menor incidente y examina cualquier detalle; en cambio, cuando llega a nuestra comarca el análisis pierde en precisión ofreciendo una visión mucho más superficial. El tema central en el sector que nos ocupa lo constituye el recorrido seguido por las tropas musulmanas en su camino a Ecija que, según él, pasaría por Puerto Serrano, tomaría el camino de la Herradura del campo y a la altura de la Posada de Plata enfilaría hacia Morón desde donde avanzaría hacia La Puebla de Cazalla que la identifica con Caruba. Del término histórico sólo nombra la ciudad de Morón que fue "un importante enclave visigodo" y Moguerejo que piensa que debió ser la antigua Callet. No ofrece noticias de hallazgos de tresors o bijoux, ni de yacimientos relacionados con estos acontecimientos como ocurre con otros lugares.

Este trabajo se inscribe, pues, dentro de la línea de estudios geográfico-históricos acerca de la invasión musulmana que en aquellos momentos se estaba llevando a cabo y que culminará bastante años después y con una metodología mucho más científica en la figura de Félix Hernández ${ }^{14}$. Algunos de aquellos artículos fueron utilizados por Bonsor en la redacción de su obra aunque su estudio se distingue del resto por la vertiente arqueológica que introduce. Hay un esfuerzo serio, aunque no riguroso, por vincular los datos de las fuentes con yacimientos y hallazgos. Por supuesto, este tipo de análisis y relación sólo podía llevarlo a cabo una persona tan bien informada sobre la realidad arqueológica de nuestra tierra como él lo estaba.

Otro de los trabajos que pueden incluirse en este período hace referencia a la ingente labor recopiladora que E. Hübner (187I) efectuó sobre la epigrafía latina de la península y particularmente sobre las inscripciones cristianas. Se trata de un trabajo en el que los objetos son analizados de manera individual sin relación contextual alguna. En lo referente a nuestra zona y al período medieval, el filólogo alemán da a conocer, por primera vez, las lápidas de época visigótica que $A$. Bohorques recogía en su obra, algunas de las cuales habían ya desaparecido. Junto a estas piezas cuya lectura fija,

\footnotetext{
13 Archivo General de Andalucía. Sección J. Bonsor. Leg. 7, p. 5. (manuscrito).

14 Precisamente este autor en uno de sus "estudios de geografía histórica española" dedica un apartado entero al análisis de Silibar situada a escasos kilómetros de Cote (Montellano). Dicho trabajo no ha sido incluido en este capítulo por estar elaborado exclusivamente sobre la base de la documentación escrita. No obstante, quede aquí su referencia HERNANDEZ JIMENEZ, F. (I96|): "Ragwal y el itinerario de Musa de Algeciras a Mérida". Al-Andalus, 26. pp. 43-I53.
} 
nos interesa destacar por el debate historiográfico que suscitó posteriormente -el único que se ha establecido sobre la etapa visigoda en nuestra zona- la publicación de un ladrillo de la serie "Marciano" descubierto hacía pocos años en el cortijo de Balbuan del cual únicamente ofrece su leyenda.

Para concluir con esta etapa sólo nos queda citar el Diccionario de P. Madoz (1898). Aunque se trata de una obra de carácter enciclopédico, en ella encontramos noticias con claro rendimiento arqueológico sobre distintas zonas de nuestro territorio que en algunos casos, dado el vacío informativo que aún mantienen determinadas áreas del término histórico, constituyen un documento excepcional y único sobre la realidad arqueológica de parte de nuestra circunscripción primitiva. Así, por ejemplo, publica por primera vez una relación de yacimientos medievales entre los que cabe destacar, entre otros, los de Gerivel, Mazmorras, Roza de Coria, Cote ${ }^{15}$ e incluso habla de "vestigios de un pueblo considerable al lado opuesto de Cote" que sin duda corresponde a la fortificación de Pancorvo.

Varias diferencias se pueden establecer entre la arqueología de esta etapa y la precedente. En primer lugar, no son personalidades locales las que producen los trabajos sobre nuestro pasado material, sino investigadores de distinta procedencia y formación. Ello supone un enriquecimiento importante con respecto a las fases precedentes, ya que los nuevos investigadores no pertenecen al estamento eclesiástico sino que son personas de profesión liberal, muchas de los cuales centran su actividad profesional en las actuaciones y estudios arqueológicos. En este sentido, hay que señalar también la influencia del krausismo en el pensamiento y formación de muchos de estos profesionales.

No se producen durante esta etapa trabajos monográficos sobre nuestra zona sino que los estudios quedan incluidos en obras gene- rales en las que a veces los temas referidos a nuestro territorio ocupan un papel más bien secundario.

Otra de las características principales de los estudios arqueológicos de finales del siglo pasado es que la gran mayoría de ellos quedaron inéditos, por lo que a pesar del interés que algunos mostraban, tanto desde el punto de vista temático como metodológico, pasaron desapercibidos para la critica posterior. Tan sólo los trabajos de F. Collantes de Terán y Caamaño fueron en parte amortizados por su nieto $y$ esto fue debido a la particular circunstancia de su parentesco. No obstante, la no publicación de estas obras indica claramente el carácter consectario que tuvieron tanto para sus autores como para la investigación de aquellos momentos.

Desde luego nada tiene que ver el panorama arqueológico andalusí de la comarca con el que se estaba desarrollando en algunos lugares de la península, entre ellos Sevilla. Se elaboraron en la capital hispalense importantes trabajos en el campo de la arqueología medieval que, por desgracia, no encontraron el eco adecuado en nuestra zona, a pesar de que algunos de esos autores mantuvieron estrechos contactos con distinguidas personalidades de la cultura de Morón e incluso llegaron a colaborar, como veremos a continuación, en la recién fundada Revista de Morón con artículos referidos a algún aspecto de la civilización medieval de nuestra tierra.

Nos referimos, por citar algún ejemplo, a Amador de los Ríos (1875) quién publica una obra sobre las inscripciones árabes de la ciudad que continúa, a pesar de su fecha, en pleno vigor y que iba precedido por un completo estudio de los epígrafes árabes de la ciudad que lo aleja algo de los estrictos inventarios filológicos característicos de la epigrafía latina. También sacó a la luz una serie de artículos sobre determinados aspectos del arte islámico de la ciudad que, sin entrar en valoraciones más 15 Algunos de estos yacimientos lógicamente son fechados incorrectamente como es el caso de Cote que la considera como una
torre romana. 
detenidas, ya que ello excede los objetivos de este trabajo, podemos considerarlos como los inicios de los modernos estudios acerca de la cultura islámica en la ciudad de Sevilla. También en este sentido hay que nombrar a J. Gestoso y Pérez quien desde la corriente del krausis$\mathrm{mo}^{16}$, como demuestra el tono pedagógico y formativo de algunas de sus obras y la convicción que emana en sus escritos de que la regeneración debía emprenderse desde la educación, aportó al campo estricto de la "ceramología" un libro de gran interés (GESTOSO, 1903). Sobre Morón publicó diversos artículos acerca de aspectos muy puntuales del castillo. No obstante, y aunque sólo sea a título de referencia, nos interesa destacar, al no haber sido debidamente valorada por el momento, la actividad como arqueólogo asesor que desarrolló en la restauración de monumentos como la Giralda, Torre del Oro etc. y que en muchos aspectos puede considerarse como precursor de la figura actual del "arqueólogo de apoyo a la restauración". Como es lógico pensar, se trata de una experiencia aislada, sin prorrogación posible, propiciada más por el crédito adquirido por J. Gestoso y la sensibilidad de arquitectos como A. Fernández que por el desarrollo metodológico alcanzado por nuestra disciplina.

\section{SIGLO XX}

Los inicios del siglo $X X$ vienen marcados por un acontecimiento de gran trascendencia en el ámbito cultural como fue la publicación de la Revista de Morón en Enero de 1914. A partir de 1917 pasó a llamarse Revista de Morón y Bético-Extremeña en clara alusión al carácter más regional que intentaba abarcar. Por último, desde el 13 de Junio de 1920 se denominó Revista Española. En todas estas etapas su director fue J. Plata y Nieto quien logró dotar a la publicación de cierto prestigio, ya que implicó a importantes personajes del mundo cultural local como el biólogo A. Cala y Sánchez y sevillano como el poeta M. Machado y Alvarez, el arquitecto A. Fernández Casanova, el arqueólogo J. Gestoso, con quienes mantenía una estrecha relación profesional. La intención de la Revista es en palabras de su director "el estudio de la región en todos los ordenes de las ciencias, de las letras y de las artes" (NIETO Y PLATA, 19|4). Ello se tradujo en una intensa actividad investigadora y en una interesante labor recopiladora que permitió la publicación o reedición de estudios sobre la comarca tanto pretéritos -se publicaron los trabajos inéditos de A. Bohorques, C. de Balbuena, F. Morilla, etc.- como contemporáneos -se reeditaron artículos de A. Cala, F. Fita, etc..- Ahora bien, todo ello "(...)se desenvolvería siempre dentro de la más estricta imparcialidad y elevándose, en cuanto le sea posible, a las regiones serenas de las ideas" (p. 2).

Al lado de los trabajos estrictamente científicos, esta revista constituyó el órgano de expresión de una burguesía agraria en pleno apogeo, cuyo florecimiento no se basaba en la modernización, ni en innovaciones especiales sino en las circunstancias favorables que atravesaba el campo y principalmente en la situación internacional del momento. En este sentido, la Revista de Morón nace de las inquietudes culturales y políticas de esta clase, de la cual se muestra claramente propalativa: "Esa burguesía agraria es la única superioridad, la fuerza vital exclusiva del pueblo en que hemos nacido, es el nervio, es la médula (...) a ella debe nuestra nación el aliento que tiene el que tuvo en otros siglos y el que haya de tener en el futuro." (GARCIA CABALLERO, 19|4).

Algunos de sus principales representantes firmaron asiduamente en secciones expresamente diseñadas para ello y dispuestas invariablemente a principio y/o final de cada número. En ellas autores como Ruiz de Zuñiga, M. García Caballero, etc. analizaban las cuestiones más diversas deteniéndose a veces en temas de buenas costumbres, urbanidad, etc. La intención y definición de la Revista queda evidente cuando comentan "Revista de Morón será española y cristiana por sus cuatro costados, que tratará de todo menos de política (...) y está dedicada a Morón, nombre que honra su por-

16 También se formó en la universidad sevillana a la sombra del profesor Federico de Castro. 
tada, porque su fin inmediato y último es laborar por su engrandecimiento moral y material." (RUIZ DE ZUÑIGA, 19|4).

La arqueología en general y la medieval en particular apenas tuvieron cabida en la Revista. Tan sólo la descripción de algunos hallazgos aislados y de una serie de artículos acerca de nuestro pasado clásico -no superan el número de seis en los ocho años de vida de la Revista y la mayoría eran reediciones de trabajos recientes ${ }^{17}$ - pueden considerarse, y no de una manera muy rigurosa, como los únicos trabajos del ámbito de nuestra disciplina que fueron recogidos por esta publicación. Contrasta con este desolador panorama el auge que, al menos en su primera etapa, adquieren los estudios geográficos de la región llegando a contar, durante algunos años, con una sección permanente dedicada monográficamente a ellos.

Una de las secciones casi permanentes de la Revista estaba dedicada a las descripciones arquitectónicas de los principales edificios de la ciudad. Estas fueron llevadas a cabo por contrastados arquitectos a petición de J. Plata. Pues bien, entre las construcciones que más llamaron la atención de los especialistas se encontraban el castillo de Morón y gracias a ello contamos en la actualidad con una serie de artículos, tanto de carácter general como sobre aspectos muy concretos, cuyo examen global, como hemos comentado, se efectuará en un trabajo próximo.

Los estudios de frontera no podían faltar en una revista local y ellos ocuparon el interés principal de las investigaciones históricas. Estos abarcaban desde la simple referencia documental, tanto de archivos locales como nacionales, hasta el análisis riguroso de cualquier tema relacionado con este período. Como resultado, se logró reunir un volumen valioso de información tanto por la cantidad de noticias recopiladas como por la calidad de las mismas.

Otro de los hitos destacados de aquellos momentos fue la publicación por R. Auñón
(1920) de Los Alkevires de Morón. En este pequeño libro de apenas cuarenta y tres páginas de extensión, el autor sintetiza todos los datos que las traducciones de los arabistas hispánicos de la segunda mitad del siglo pasado habían sacado a la luz sobre la kūra de Morón desde la conquista musulmana hasta la subida al trono de 'Abd al-Raḥmān I. Constituye, por tanto, una excerpta de noticias de gran interés sobre la primera etapa de la dominación islámica en nuestra tierra que no ha sido suficientemente valorada ni empleada correctamente por la historiografía posterior. Al margen de la estricta recopilación documental el marqués de Pilares en ocasiones intenta, sobre la base de argumentos fonéticos que a veces llegan a ser auténticamente frusleros, determinar el lugar exacto donde ocurrieron los principales acontecimientos del período de invasión relacionados con Morón y su primitiva circunscripción. La intención última del autor con esta indagación fue, como él mismo manifiesta en el capítulo final del libro, contribuir a la elaboración de un pasado glorioso de su tierra natal. Este afán localista le llevó a formulaciones poco serias, a forzar en ocasiones los datos de manera irritante. El resultado final de estas pesquisas fue en la mayoría de los casos bastante irrisible aunque ello no nos debe llevar, como a veces ha ocurrido, a desacreditar de manera general la obra, pues en otros muchos aspectos tuvo un extraordinario valor.

A lo largo del siglo $X X$ pueden apreciarse, desde el punto de vista temático y metodológico, cuatro corrientes de estudios en el campo de la arqueología medieval. Se trata de líneas de trabajo aisladas que muy pocas veces establecieron lazos de comunicación entre sí a pesar de que algunos autores trabajaron indistintamente en varias de ellas.

La época hispanovisigoda fue la primera dentro del período medieval en tomar carta de naturaleza en el campo de la arqueología. Así, pues, hay que remontarse hasta los años treinta para encontrar los primeros trabajos (MARTíNEZ SANTAOLALLA, 1934) en los que se

17 El artículo sobre los Callenses Aeneanici de F. Fita fue publicado por partes en los tres primeros números de la Revista. 
intenta sistematizar los conocimientos adquiridos acerca de algunas de sus manifestaciones culturales. En estos estudios, cuya implicación ideológica es patente (OLMO, 1991), además de establecer las convenientes tablas tipológicas sobre determinadas cuestiones artefactuales se avanza en definir las influencias y los orígenes de las expresiones materiales de aquel período. Ello dió lugar a una vasta disputa entre los que apoyaban las teorías germanistas (J. Martínez Santaolalla, Taracena, etc.) y los que apuestan por las influencias del substrato hispanorromano (Gómez Moreno, Camps Cazorla, etc.).

En nuestra zona el período hispanovisigodo contó, en las primeras décadas de este siglo, con varios trabajos publicados en revistas nacionales que tenían como única finalidad dar a conocer, mediante descripciones muy sucintas (FITA, 1908), piezas aparecidas en nuestro término que casi siempre pertenecían a ladrillos de la serie Salvo Episc. Marciano. Estos hallazgos se debían en su mayor parte a la labor investigadora y recopiladora de I. de Torres y León. Precisamente, a la inquietud científica de este autor debemos el único estudio monográfico (TORRES Y LEÓN, 1914) sobre los ladrillos de Balbuan. En él se transciende del mero ámbito descriptivo y se procede a examinar los contenidos simbólicos de la decoración, su procedencia, etc. El resultado final fue muy desigual pero permitió, entre otras cuestiones, fijar la fecha de fabricación, establecer la relación entre la inscripción Marciano y el obispo astigitano del mismo nombre, determinar su centro de fabricación en el cortijo de Balbuan, etc.

I. de Torres analiza estos materiales como una prolongación del mundo romano; de ahí que el estudio de estas piezas le sirva para volver sobre el consabido tema de los Callenses Aeneanici al cual dedica varias páginas. Lamentablemente, este artículo no encontró continuadores y supuso el temprano canto del cisne de la historiografía arqueológica visigoda en nuestra comarca a pesar de la problemática del lugar, próximo al linde bizantino, del interés de las series epigráficas existentes y del descubrimiento de nuevos hallazgos a lo largo del siglo. Ni siquiera volverán a emprenderse tra- bajos en este campo durante el apogeo que conocerán estos estudios en los años cincuenta y sesenta a raíz de la apropiación ideológica que el régimen hizo de este período, al pretender retrotraer a los reinados de Leovigildo y Recadero los precedentes históricos de la Unidad política, religiosa y territorial de España. Quizás ello se debe en parte a que el referente ideológico de toda la Comarca Sur con respecto al pensamiento político de aquellos momentos era, como no podía ser de otra manera, la etapa de frontera, entendida como "(...) la fase final de la gesta de la unidad de España". Así, pues, no nos debe extrañar que los sucesos políticos de aquellos últimos siglos medievales ocuparan casi monográficamente las páginas históricas de las dos únicas revistas locales que vieron la luz en aquellos difíciles años: El Gallo y Arunci ambas editadas en 1955.

Ya hemos comentado que la publicación de la Revista de Morón constituyó uno de los acontecimientos culturales más importantes de las primeras décadas del siglo. En ella se implicaron, bajo la acción tutelar de su director, importantes personalidades de las ciencias y de las letras, que llevaron a cabo de forma sistemática interesantes investigaciones sobre nuestro territorio y su cultura. La Revista tenía una vocación científica que intentaba aunar con una difusión popular. La línea de investigación se desarrollaba siempre dentro de la más severa matriz positivista donde la descripción pormenorizada de los hechos u objetos conformaban el argumento exclusivo de los trabajos.

Una de las secciones principales de la Revista estaba dedicada a la descripción de los principales monumentos de la ciudad. En ella publicaron investigadores de la talla de A. Fernández Casanova, J. Gestoso, etc. Pues bien, la edificación que más interés despertó entre los especialistas fue, con diferencia, el castillo y a ello no fue ajeno la figura de I. de Torres o Hipólito Klever, seudónimo con el que, a veces, gustaba firmar sus trabajos. Gracias a ello contamos con una vasta relación de descripciones efectuadas desde diferentes puntos de vista y de valores muy desiguales. No obstante, el tratamiento general de estos trabajos siempre era el mismo, a saber: publicación de varias foto- 
grafías, algunas de las cuales, a tenor de las demoliciones posteriores que ha sufrido la fortaleza, constituyen el único documento que nos ha quedado sobre determinados lienzos y torres. A esta documentación gráfica le acompaña siempre una escueta descripción de los elementos más importantes o llamativos y, a veces, una breve relación de los acontecimientos políticos más destacados asociados al devenir del recinto murado. Naturalmente el panorama de esta "castellología" nada tiene ver con los avances que se estaban produciendo en otros lugares de Europa (MORA-FIGUEROA, 1994) pero ésta era la situación general en la que se hallaban los estudios sobre castillos, al menos en el área meridional (MORA-FIGUEROA, 1990, pp. 50-5I) de nuestro país, como demuestran los trabajos que en este mismo sentido y de forma simultánea se estaban realizando en Jaén (SALVATIERRA, 1990, pp. 44-45) y Carmona (IIMÉNEZ MARTíN, 1989, pp. 150-155).

La línea de investigación de estos trabajos, como hemos comentado, se enmarca dentro de una matriz estrictamente positivista en la que predomina el puro examen descriptivo realizado desde un plano rigurosamente sincrónico, por lo que no existe posibilidad alguna de transcender el análisis hacia cuestiones tales como el origen de la fortificación, la evolución de su perímetro, aspectos funcionales de ciertos elementos, etc. Tampoco se aprecian en estos estudios ensoñaciones románticas, evocaciones pretéritas, ni deslizamientos pintorescos que hubiesen desvirtuado sus objetivos y que, por lo demás, fueron tan habituales en este tipo de trabajo hasta bien entrado el siglo.

A excepción de J. Gestoso la actividad profesional de todas las personalidades que se ocuparon del castillo era la arquitectura; profesión que prácticamente ha monopolizado los estudios de edificaciones andalusíes hasta nuestros días. Ello permite en la actualidad contar con un conocimiento suficiente y contrastado sobre distintas cuestiones relacionadas con el comportamiento arquitectónico y funcional de las fortalezas en general y de sus principales ele- mentos en particular. Dentro de esta línea hay que señalar, junto a los ya mencionados, a $M$. González Simancas, V. Lampérez y Romea y, por supuesto, a L. Torres Balbás con quien estos estudios alcanzan madurez cientííca. No obstante, el principal problema que plantea esta corriente es que ha circunscrito estos trabajos al ámbito de la historia del arte, no posibilitando avanzar hacia análisis relacionados con la organización social, territorial, etc. que también se desprenden, tras un examen adecuado, de estas manifestaciones materiales. Esta es una cuestión que aún hoy sigue arrastrando esta rama de la arqueología medieval.

Esta corriente analítica alcanza, en lo que a nuestro castillo se refiere, su colofón final a mediados de siglo con F. Collantes de Terán Delorme. Este autor llevó a cabo una descripción exhaustiva de la fortaleza, donde junto a los datos estrictamente literarios unía una serie de croquis que apoyaba con comentarios escritos. También se sirvió de una amplia documentación histórica extraída principalmente de los archivos locales. Todo ello enriqueció considerablemente el nivel de las conclusiones finales. A pesar de que este trabajo sigue moviéndose en el positivismo ecléctico en el que predomina la acumulación de descripciones como único medio de generar síntesis histórica, también se aprecian, por primera vez, intentos serios de trascender el puro examen analítico y avanzar en una lectura diacrónica del edificio e incluso relacionar el recinto defensivo con elementos que se encuentran en su interior como aljibes, etc. Este trabajo debió ser publicado en el Catálogo Arqueológico y Artístico de la provincia de Sevilla que venía realizando junto a J. Hernández Díaz y A. Sancho Corbacho pero al quedar interrumpida la edición en el tomo tres, concretamente en la ciudad de Carmona, ha permanecido inédito hasta nuestro días ${ }^{18}$.

F. Collantes de Terán supone la introducción de la "moderna arqueología" en nuestra provincia y, lo que es más importante para nosotros, la difusión de la arqueología medieval ${ }^{19}$;

18 COLLANTES DE TERAN DELORME; F: Archivo manuscrito personal. En la actualidad se halla depositado en el Departamento de Prehistoria y Arqueología de la Universidad de Sevilla. 
la cual sitúa, a pesar de la falta de tradición historiográica, al mismo nivel que la arqueología clásica o prehistórica. El método de investigación que aplica para la arqueología medieval era el mismo que empleaba en la clásica; a excepción, claro está, del análisis documental que, dada su relación con el profesor J. de M. Carriazo, dominaba perfectamente. Fue, precisamente, la inclusión de estos apéndices documentales acerca de los restos medievales una de las causas que le permitió transcender del estricto examen arquitectónico o artefactual y avanzar en el estudio de la problemática histórica en la que se hallaban inscritas aquellas manifestaciones materiales.

En nuestra comarca los trabajos medievales no se limitaron al castillo de Morón sino que abarcaron, dentro de la misma línea descriptiva, otros campos de sumo interés, como el estudio del sistema de fortificaciones que comprendía la denominada Banda Morisca y la "Carta arqueológica" del término. Precisamente, estas dos líneas de investigación abiertas por F. Collantes de Terán serán las únicas que se mantengan en nuestro territorio durante la segunda mitad del siglo.

Los estudios sobre las torres y castillos esparcidos a lo largo de la marca con el reino nazarí constaban de las siguientes partes: una recopilación documental que incluye noticias de archivos e historiografías locales aunque siempre de forma muy selectiva y contrastada, descripción de los restos arquitectónicos conservados y documentación gráfica consistente en un plano de planta de las edificaciones y un completo reportaje fotográfico. En sus apuntes de campo, depositados en el Departamento de Prehistoria y Arqueología de la Universidad de Sevilla, se conservan además algunos comentarios sobre cuestiones particulares de la edificación, croquis de detalles de ciertos elementos, etc. que no fueron recogidos en sus publicaciones y que, en ocasiones, resultan de un gran interés. Lamentablemente, la mayor parte de estos trabajos nunca se editaron; de modo que sólo llegaron a ver la luz y no en las condiciones que hubiese deseado su autor el trabajo referido al castillo de Cote (COLLANTES DE TERÁN DELORME, 1973) y otro, de carácter más general, acerca de los castillos del Reino de Sevilla (COLLANTES DE TERÁN DELORME, 1953) donde incluye de forma muy sintética algunos estudios sobre aquellas fortificaciones de la Banda Morisca que estaban bajo la jurisdicción del concejo hispalense.

Años después se retomarán otra vez los estudios sobre las construcciones defensivas de la Banda Morisca pero desde un punto de vista nuevo que irá poco a poco perfilando una metodología específica de análisis que terminará imponiéndose en la región hasta el punto de que la casi práctica totalidad de los trabajos que en los últimos años se han llevado a cabo se han efectuado desde esta propuesta metodológica. La figura principal de esta corriente es L. de Mora-Figueroa, cuyo primer trabajo al respecto se centró en el castillo de las Aguzaderas (MORA-FIGUEROA, 1973) aunque en él aún se aprecia una organización descriptiva similar a las empleadas hasta entonces con la única salvedad de incluir una búsqueda de paralelos tanto peninsulares como europeos que hasta entonces no se había realizado en las edificaciones de nuestra región.

No obstante, ya hemos comentado que quizás el aspecto más destacado de estos trabajos fue el posibilitar avanzar en la definición de un nuevo esquema metodológico para el estudio de estas fortificaciones (MORA-FIGUEROA, 1986). Esta propuesta, al margen de organizar de forma coherente y racional las informaciones sobre los castillos, llama la atención sobre una serie de cuestiones que hasta entonces habían pasado desapercibidas como, por

\footnotetext{
19 Las actuaciones más significativas de su actividad como arqueólogo medievalista se localizan en la capital hispalense. Así, por ejemplo, en 1957 presenta su tesis doctoral sobre la topografía de la "Sevilla antigua y medieval" donde se recoge, por primera vez, un estudio de conjunto sobre la Sevilla musulmana desde el punto de vista arqueológico. Los temas centrales de la Memoria, en lo que a la ciudad andalusí se refiere, fueron la delimitación exacta del trazado de la muralla, el estudio de la Buhayra y los caños de Carmona y el análisis de una serie de restos aislados. También a este personaje se debe la realización de las primeras excavaciones medievales en Sevilla. Nos referimos a las intervenciones en la calle Cuesta del Rosario, Plaza de Villasís esquina calle Laraña, en el Patio de los Naranjos, transcoro de la Catedral, arco de San Miguel y Buhayra; esta última con J. Zozaya.
} 
ejemplo, la descripción de los accesos y caminos históricos y actuales al castillo, los acondicionamientos poliorcéticos, etc. También sistematiza el estudio de las influencias y paralelos espaciales y temporales, e incluso extiende, aunque tímidamente, el análisis al territorio mediante un apartado dedicado a los enlaces ópticos. En resumen, podemos afirmar que la implantación de este método ha permitido homogeneizar metodológicamente los estudios sobre las torres y castillos de la Banda Morisca, a la vez que los introducía de lleno en el ámbito de la "castellología moderna".

Entre los trabajos más destacados de esta línea de investigación cabe señalar, además de los ya citados, los dedicados a Cote (MORAFIGUEROA, 1985-86), Olvera (ROJAS GABRIEL, 198586), Lopera (ROJAS GABRIEL, 1987), Torre EstreIla (FRESNADILLO y VALDECANTOS, 1987), etc. Incluso existe para el castillo de Morón un trabajo elaborado en esta línea metodológica realizado por C. Montes Gómez que, por desgracia, nunca fue publicado.

La última vía de investigación que se desarrolla en nuestra comarca, en lo que a la arqueología medieval se refiere, durante la segunda mitad del siglo $X X$ hace alusión al territorio. Más que análisis territoriales he optado por denominar a esta corriente con el ambiguo nombre de "Cartas arqueológicas", título con el que aparecieron publicados los dos únicos trabajos editados que abarcaban parte del término histórico de Morón.

Esta línea de trabajo también tiene sus precedentes en F. Collantes de Terán quien llevó a cabo sobre la década de los años cincuenta una prospección superficial y selectiva del término histórico basándose principalmente en las noticias historiográficas y la relación de hallazgos aislados que se habían producido en los últimos siglos. Logró de esta forma identificar más de cuarenta yacimientos, la mayoría de los cuales pertenecían al período clásico, aunque también pudo descubrir cerca de diez asentamientos adscribibles a la etapa medieval. Se trata de un inventario estricto de localizaciones, en cada una de las cuales enumera de una manera sucinta los restos muebles e inmuebles más sobre- salientes que aún conservaban y que le sirven para precisar su cronología. En ocasiones se detiene en intentar determinar, basándose en los hallazgos epigráficos y numismáticos aparecidos, el municipio romano al que podían corresponder algunos de los yacimientos de la comarca. Quizás el aspecto más interesante de este trabajo radica en las relaciones que el autor llega a establecer entre los datos suministrados por la documentación escrita de los archivos locales y ciertos asentamientos medievales, en su mayoría pertenecientes al período de frontera con el reino nasrí.

Al margen de estas reflexiones, el trabajo se ciñe al rígido campo descriptivo, de modo que no se localizan ni teoría sobre la distribución del poblamiento de un período concreto, ni análisis espacial alguno. Constituye un listado de yacimientos en la línea de las obras que años después llevaron a cabo Ponsich (PONSICH, 1973) y Didierjean (DIDIERJEAN, 1979) para otras zonas del valle del Guadalquivir.

Como buena parte de las investigaciones efectuadas por F. Collantes de Terán, estos trabajos tampoco vieron la luz $y$, aunque fueron utilizados por investigadores posteriores tampoco alcanzaron la difusión que merecían sobre todo en términos como Morón, Arahal, Puebla de Cazalla que continúan estando indocumentados en este campo.

No será hasta 1985 cuando se publique la primera "Carta Arqueológica" que aborde el análisis de parte del término histórico de Morón, concretamente el sector Suroccidental del mismo. Este trabajo constituyó la Tesis de Licenciatura de M. Mª Ruiz (1985) y se inscribía dentro de "...la línea de investigación del Departamento de Prehistoria y Arqueología de la Universidad de Sevilla como paso previo al conocimiento y evolución del poblamiento de Andalucía Occidental desde la primera presencia humana hasta el medievo". El marco espacial que abarca es estrictamente geográfico como su título indica: La zona Sureste de la campiña sevillana. En ella se incluyen yacimientos pertenecientes a las circunscripciones de El Coronil, Arahal, Morón y Montellano. Los datos son presentados conforme a un esquema inva- 
riable en el que se recogen los siguientes apartados: nombre del yacimiento, coordenadas en U.T.M., relación bibliográica si existiese, referencia literaria de su situación, descripción detallada de los hallazgos y valoración crítica en la que se insiste en su adscripción cronológica. El autor individualiza un total de 123 asentamientos de los cuales sólo 46 muestran restos pertenecientes a época medieval. Los yacimientos medievales están clasificados en dos amplios grupos según correspondan al mundo visigodo o a la etapa islámica.

Al final del libro ofrece una pequeña reflexión por etapas históricas acerca del comportamiento poblacional de estos asentamientos. En lo que respecta al mundo medieval comenta las siguientes cuestiones: En época visigoda los yacimientos son muy escasos y casi todos corresponden a necrópolis. Sólo tres localizaciones tienen entidad de poblado y estas son continuación de grandes núcleos romanos. En el período andalusí el poblamiento es bastante débil y extensivo siendo la media de un asentamiento cada nueve kilómetros. No obstante, durante esta fase se palia algo el despoblamiento producido en la zona en época visigoda. La mayoría de ellos reutilizan yacimientos anteriores y tan solo dos muestran cierta entidad. En la etapa de frontera se produce una modificación radical de los asentamientos con respecto a las etapas precedentes.

La siguiente "Carta arqueológica" se centra exclusivamente en el término municipal de Montellano (ORIA et alii, 1990). Metodológicamente mantiene el mismo esquema que la anterior. Los autores llegan a identificar 65 yacimientos de los cuales tres pertenecen a época visigoda, siete son hispanomusulmanes y uno moderno. Las conclusiones a las que llegan los autores acerca del panorama ocupacional medieval en esta zona montañosa son, en síntesis, las siguientes: en el período visigodo se produce un acentuado despoblamiento con respecto a la etapa clásica. Tan sólo se mantienen algunos pequeños núcleos situados en tierras bajas contiguas a la sierra lo que les hace suponer que estaban orientados hacia la explotación agraria. En la fase hispanomusulmana se mantiene la fuerte disminución de la población "aunque se asiste a una radical transformación de las pautas de asentamiento". Según los autores estas pautas pueden ser similares a las analizadas en el Levante peninsular (BAZZANA, 1982; BAZZANA et alii, 1988) por lo que establecen una primera categoría de fortificaciones a la que correspondería el castillo de Morón "como centro del poder político-religioso que organiza el territorio". Junto a él una serie de plazas de menor entidad como Las Aguzaderas, etc. que protegerían a hábitats cercanos. Todo esto respecto a las tierras bajas; en la Sierra presupone una importante presencia de elementos beréberes en la que las torres como Lopera, Cote, etc. tendrían una importante misión como refugio de estas poblaciones semiestables de carácter tribal.

En la última etapa medieval, correspondiente a la fase de frontera, se detienen algo más, ya que cuentan con un volumen amplio de estudios basados principalmente en la documentación escrita: "Las fuentes de información disponibles para esta época permiten esbozar no sólo un esquema general de la implantación humana sobre el territorio sino que nos informan acerca de su dedicación específicamente militar" (p. 133). Este período se caracteriza principalmente, según ellos, por lo reducido de los efectivos humanos concentrados en unos cuantos puntos estratégicos de fácil defensa y en la función militar desempeñada por las poblaciones asentadas en estos núcleos como consecuencia de los avatares de la frontera.

Ambos libros, como ya hemos insinuado, están elaborados desde el mismo plano metodológico ${ }^{20}$; de ahí que consideremos adecuado establecer la recesión crítica de ellos de manera conjunta. Todos estos estudios se inscriben en una propuesta sistemática de trabajo llevada a cabo por el Departamento de Arqueología de la Universidad de Sevilla, el cual

\footnotetext{
20 Por estas mismas fechas se llevó a cabo por parte de la Delegación Provincial de Cultura de la Junta de Andalucía una prospección superficial del término que al estar centrada exclusivamente en los dolmenes no será analizada en este apartado. BARRIONUEVO, F.J. y J. DE LA ASCENSION, J de la: Catálogo de dolmenes de la Provincia de Sevilla. (Delegación Provincial de Cultura, inédito).
} 
a su vez mantenía una línea de investigación centrada fundamentalmente en el calcolítico, protohistoria y período clásico. Ello queda reflejado en la formación de la mayoría de los autores de estas "Cartas"; de ahí que el período medieval, aunque se incluye, ocupe un papel claramente secundario dentro del conjunto de la obra. Por otro lado, las descripciones de los yacimientos y de sus hallazgos en lo que respecta a la etapa medieval no son lo minuciosas que cabría esperar y la documentación gráfica que a veces acompaña también es bastante incompleta, por lo que con frecuencia no es posible, a través de los datos publicados, poder concretar mucho más sobre los yacimientos. Parte de la responsabilidad de esta situación es achacable a la ausencia de especialistas medievales en los equipos que efectuaron estas prospecciones o que las asesoraron. Ello se evidencia, además de manera pasmosa, en la adscripción temporal que atribuyen a los yacimientos. Todos son clasificados como musulmanes sin mayores concreciones cronológicas. Esta generalización pone en entredicho cualquier conclusión a la que pudieran llegar. Naturalmente al carecer los equipos de arqueólogos medievalistas los problemas más importantes respecto a la ocupación y organización del territorio andalusí no son recogidos en el estudio final de estas actuaciones.

Hasta aquí el relato, más o menos detallado, de las actividades arqueológicas en el término histórico de Morón a lo largo del siglo $X X$. De todo ello podemos inferir con relación al comportamiento de la arqueología medieval en el ámbito nacional las siguientes conclusiones. En primer lugar, llama la atención la escasa, por no decir nula, incidencia que tuvieron en nuestra zona las principales corrientes de investigación que se desarrollaron en el campo temático o a título individual. La ausencia de colecciones epigráficas o numismáticas, de conjuntos edilicios andalusíes de singular carácter monumental, etc. hizo que pasara desapercibida nuestra zona para la crítica contemporánea. En este sentido, la única opción que llega a concretarse de forma continuada, muy avanzada la segunda mitad del siglo, hace referencia al complejo defensivo que se establece contra el reino granadino. No obstante, queda por ver si estos estudios individuales pueden consolidar un programa sistemático de actuaciones que produzca las convenientes síntesis monográficas. Tampoco a escala espacial las nuevas líneas de investigación tuvieron reflejo en nuestra área perdiéndose una buena oportunidad para introducir los debates de la arqueología espacial andalusí con la realización de las "Cartas arqueológicas".

Precisamente, la situación marginal de nuestra zona con respecto a la arqueología peninsular provocó que no se produjeran excavaciones hasta bien entrados los años ochenta. Estas actuaciones estuvieron siempre dirigidas hacia elementos funerarios prehistóricos que se hallaban en un estado pésimo de conservación (GIL et alii, 1985) o que corrían el peligro de ser destruidos (CRUZ-AUÑON y RIVERO, 1990). Son intervenciones puntuales que no tienen continuación posible. En la arqueología medieval, como siempre más retrasada, aún se tardará algunos años más en efectuar las primeras excavaciones. Estas se producen en los años noventa pero a diferencia de las anteriores tuvieron continuidad temporal al quedar incluidas como actuaciones previas al Proyecto de Restauración que en aquellos años se llevaba a cabo en el castillo de Morón. No obstante, tanto el proyecto como las actuaciones estaban ligados al interés particular de algunos responsables de la administración municipal, de modo que con la reorganización que se produjo tras las elecciones de 1991 las excavaciones y el proyecto quedaron suspendidos inmediatamente.

Desde fines del siglo pasado se percibe en nuestra zona el desarrollo de una arqueología medieval inserta en la arqueología prehistórica y clásica como demuestra el hecho de que fuera precisamente de aquellos campos de donde provenía la mayoría de los autores que elaboraron los primeros trabajos de esta disciplina. Estos investigadores, en un principio, sólo efectúan incursiones puntuales; las cuales se realizan con las mismas proposiciones metodológicas con las que trabajaban en el mundo romano. No obstante, conforme transcurre el siglo XX se aprecia cómo se van concretando formulaciones propias y específicas que no terminarán de consolidar hasta bien entrada su 
segunda mitad. Ahora bien, en ningún momento de este desarrollo se plantea la posibilidad de establecer construcciones históricas con los datos aportados por estos estudios. En ellos predomina aún la matriz descriptiva donde la pura acumulación se consideraba suficiente para generar conocimiento histórico.

La restauración y reconstrucción de monumentos en España se centró, hasta bien avanzado este siglo, únicamente en edificios religiosos, en conjuntos monumentales andalusíes de cierta entidad o edificaciones singulares bien conocidas a través de la historiografía. En este último caso podemos decir incluso que el carácter patrimonial lo conferían más las crónicas que los restos arqueológicos existentes ${ }^{21}$. Lógicamente, esta situación tiene su perfecta proyección en nuestra zona cuyos pueblos ven, durante este siglo, perder buena parte de su conjunto histórico. En el caso concreto del castillo de Morón, por ejemplo, se mantiene la política de destrucción sistemática del perímetro murado ante cualquier amenaza de ruina. El vasto espacio interior de la fortaleza se utiliza hasta los años setenta para ubicar los sistemas de equipamiento público. Ello provocó el aniquilamiento de algo más de la mitad de la alcazaba, de la basíica y el cementerio altomedieval, etc.

Podemos, por tanto, decir que no será hasta bien avanzados los años ochenta cuando comienzan a generalizarse en nuestra comarca los estudios de arqueología medieval, lo cual se constata también en otros lugares de nuestra región. A este fenómeno no fue ajena la transferencia de las competencias en materia de cultura que en aquellos años se confiere a la recién creada Junta de Andalucía, el resurgir de un cierto sentimiento nacional/regional que se traduce en la publicación de un buen número de historias de carácter regional o provincial e incluso algunos libros que intentan definir ideológicamente esas manifestaciones andalucistas (ACOSTA, 1979) y, por supuesto, el tratamiento preferente que recibió el período andalusí como elemento peculiar y diferenciador de nuestra tierra 22 en unos momentos donde cualquier manifestación que incidiese en la identidad particular de Andalucía era bien acogido por amplios sectores sociales.

En definitiva, la arqueología medieval en nuestro territorio conoció un atraso considerable respecto a las propuestas metodológicas efectuadas en otros lugares de la Península. Ya hemos comentado que la falta de centros de investigación capaces de canalizar y difundir los avances en este campo y la ausencia de manifestaciones materiales que por su singularidad o monumentalidad llamarán la atención de los especialistas fueron en buena parte los responsables de esta situación. Ahora bien, este panorama pensamos que puede ser generalizado a otras áreas de nuestra región. Las actuaciones, pues, dentro de esta disciplina se caracterizan aquí por constituir esfuerzos aislados y excepcionales incapaces de consolidar equipos comprometidos a largo plazo.

Por último, se debe señalar la escasa, por no decir nula, aportación que han tenido los datos arqueológicos en la elaboración de las síntesis historiográficas o en los estudios particulares que de esta zona se han realizado. Esta circunstancia, común hasta hace algunos años a buena parte de la arqueología medieval, puede explicarse por múltiples razones. Una de ellas fue la ausencia de propuestas metodológicas propias y directamente relacionadas con la problemática histórica en la que se hallaban incluidas las intervenciones. La copia literal de los métodos positivistas de la arqueología clásica y prehistórica sumió a la arqueología medieval en problemas tipológicos o simplemente artísticos que poco o nada aportaban a los debates sociales, económicos e incluso algunos metahistóricos que venía planteándose el medievalismo tradicional.

\footnotetext{
21 Los avatares administrativos que ha experimentado la Buhayra de Sevilla es un buen ejemplo al respecto (VERA et alii, I998). 22 El exponente más extremo y radical de esta manifestación lo constituye el libro de MEDINA, A. (1979): Historia nacional de Andalucía y el andalucismo., I-II. Sevilla,
} 


\section{BIBLIOGRAFIA}

ACOSTA, J. (1979): Historia y cultura del pueblo andaluz. Barcelona.

AMADOR DE LOS RIOS, R. (I 875): Inscripciones árabes de Sevilla. Madrid.

AUÑON, R. (1920): Los Alkevires de Morón. Ed. de M. Vera y J.D. Mata. Morón de la Frontera, 1998.

BARBOSA, A. (| 6 | I): Dictionarium Lusitanico-Latinum (...) cum copiosissimo latini sermonis indice, necnon libello uno aliquarum regionum, civitatum, oppidorum, fluuiorum, montium et locorum quibus ueteres uti solebant. Basto, Bracharae.

BARRIONUEVO, J. y ASCENSION, J. de la: Catálogo de dólmenes de la Provincia de Sevilla. (Delegación Provincial de Cultura, inédito).

BAZZANA, A. (1982): "Aproche d'une tipologie des edificies castreux de l'ancien Sharq al-Andalus". Chateaux Gaillard. Estudes de Castellologie, 9-10. pp. 301-328.

BAZZANA, A. et alii (1988): Les Chateaux ruraux d'AlAndalus. Madrid.

BOHORQUES, A. (1994): Anales de Morón. Transp. del autógrafo (| 633-1642). Introd., notas e índices de J. Pascual. Universidad de Cádiz.

BONSOR, J. (manuscrito inédito): Les itineraires de l'invasion musulmana en Andalousie. Fouilles et tresors.

CANDAU Y PIZARRO, F. (1894): Prehistoria de la provincia de Sevilla. Sevilla.

CAÑAL Y MIGOLLA, C. (I 894): Sevilla prehistórica. Yacimientos prehistóricos de la provincia de Sevilla. Sevilla.

CAÑAL Y MIGOLLA, C. (1896): Nuevas exploraciones de yacimientos prehistóricos de la provincia de Sevilla. Sevilla.

CARO, R. ( 1634): Adiciones al principado y antigüedades de Sevilla y su convento jurídico. Ed. J. Hazañas y la Rúa en 1932. Sevilla.

COLLANTES DE TERÁN Y CAAMAÑO, F. (1990): Historia de Morón de la Frontera. Introd. A. M. Bernal y M. García. Sevilla.

COLLANTES DE TERAN DELORME, F. (1953): "Los castillos del Reino de Sevilla". Archivo Hispalense, 58-59. Sevilla. pp. | 17-185.

COLLANTES DE TERAN DELORME, F. (1973): "El Castillo de Cote". Estudio de Arte Sevillano. n extraordinario. Sevilla. pp. 55-65.

COLLANTES DE TERAN DELORME, F. (inédito): Archivo manuscrito personal. Depositado en el Departamento de Prehistoria y Arqueología de la Universidad de Sevilla.

COVARRUBIAS, S. de (|66|): Tesoro de la lengua casteIlana o española. Ed. facs. Turner; Madrid, 1979.
CRUZ-AUÑON, R. y RIVERO, E. (1990): "Necrópolis de cuevas artificiales en Montegil (Morón de la Frontera, Sevilla)". Anuario Arqueológico de Andalucía, 1988-III. Sevilla. pp. 279-282.

DIDIERJEAN, F. (1979):: "Archeologie aerienne dans la province de Seville. Premiers resultats". Mélanges de la Casa de Velázquez, XV. Paris.

DIRKSEN, W. (1857): Ein Beitrag zur Ausleng der epigraphischen Urkende einen Städteradnung für die Bürgergemeinde zu Salpensa. Berlin.

DOMINGUEZ, A. (|98I): Autos de la Inquisición de Sevilla (Siglo XVII). Sevilla.

DOZY, R. (|88|): Recherches sur l'histoire et la literature de l'Espagne au Moyen Age. 2 vols. Leiden.

DOZY, R. ( 1 864): Historia de los musulmanes españoles. Trad. y anotada por F. Castro 4 vols. Madrid.

FERNANDEZ, P. (|99|): Arabismo español del siglo XVIII: origen de una quimera. Madrid.

FITA, F. ( 1887): "Los Callenses Aeneanici del Arahal y Montellano". Boletín de la Real Academia de la Historia, XXXI. Madrid. pp. 38|-390.

FITA, F. (1908): "Inscripciones romanas y visigóticas de Tarifa, Ronda y Morón de la Frontera". Boletín de la Real Academia de la Historia, LIII. Madrid. pp. 344-353.

FLOREZ, E. (1773): Medallas de las colonias, municipios y pueblos antiguos de España, hasta hoy no publicadas con las de los reyes godos. 3 vols. Madrid.

FLORIAN DE OCAMPO, C. (I578): Los cinco primeros libros de la Crónica General de España. Alcalá de Henares.

FRESNADILLO, R. y VALDECANTOS, R. (1987): "EI Castillo de Torre Estrella (Medinasidonia, Cádiz)". II Congreso de Arqueología Medieval Española, II. Madrid. pp. |77-| 87.

GARCIA CABALLERO, M. (19|4): "Ideales de Morón". Revista de Morón, II. Morón de la Frontera. pp. 6-।I.

GARCÍA FERNANDEZ, M. (1992): "Historiografía moronense". Desde La Frontera, 5. Morón de la Frontera. pp. $51-60$.

GAYANGOS, P. de (1964): The history of Mohammed dinasties in Spain by Ahmad Ibn Mohammed al-Makkari. 2 vols. New York.

GESTOSO, J. ( 1903): Historia de los barros vidriados desde sus orígenes hasta nuestros días. Sevilla.

GIL, S. et alii (1985): "El sepulcro de galería de "El Hoyo del Gigante" (Morón de la Frontera, Sevilla)". Huelva Arqueológica, VII. Huelva. pp. 265-292.

GUTIERREZ BRAVO, P. ( I 765): Noticia geográphico-histórica de una inscripción romana descubierta por setiembre de 1764 en el término de la villa de Arahal y de otras piedras y medallas geográphicas inéditas. Sevilla. 
HERNANDEZ JIMENEZ, F. (196|): "Ragwal y el itinerario de Musa de Algeciras a Mérida." Al-Andalus, 26. pp. 43-153.

HÜBNER, E. (| 87| I): Inscriptiones Hispaniae Christianae. Berlín.

JANER, J.J. y ZAFRA, D. de (1858): Historia de la villa de Morón de la Frontera. Morón de la Frontera.

JIMENEZ, A. (1989): La puerta de Sevilla en Carmona. Sevilla.

JONES, J.H. (1858): History of the Conquest of Spain b. Ibn abd el-Hakem. Gotinga.

LYNCH, J. (1975): España bajo los Austrias. 2 vols. Madrid.

MADOZ, P. (1898): Diccionario geográfico-estadístico-histórico de España y sus posesiones de Ultramar. Tomo IX, Madrid.

MANZANARES, M. (1972): Arabistas españoles del siglo XIX. Madrid.

MARTIN DE ROA (1617): Santos Honorio, Eutichio, Estevan, patronos de Xerez de la Frontera. Nombre, sitio, antiguedad de la ciudad, valor de sus ciudadanos. Sevilla.

MARTIN GOMEZ, C. (1982): "Placas decoradas de época paleocristiana y visigoda, con inscripción, del Museo Arqueológico de Sevilla". Museos, I. pp. 37-43

MARTINEZ SANTAOLALLA, J. (1934): "Notas para un ensayo de sistematización de la arqueología visigoda en España. Períodos godo y visigodo". Archivo Español de Arqueología, X. Madrid. pp. 139-176.

MEDINA, A. (1979): Historia nacional de Andalucía y el andalucismo. vols I-II. Sevilla.

MOMMSEN, T. ( 855): "Die stadtrechte der lateinischen Gemeinden Salpensa und Malaca in der provinz Baetica". Abhandlungen der Sächsischen der Wissenschaften. 3,361.

MORA-FIGUEROA, L. de (1973): "El castillo de Las Aguzaderas, provincia de Sevilla". Castillos de España, I I (78). Madrid

MORA-FIGUEROA, L. de (1985-86): "EI donjon tetrabsidal del Castillo de Cotte (Montellano, Sevilla) (I.P.C.E./I.B.I./D.G.B.A.E,SE-I, I-Ca-059-EM-R3)". Estudios de Historia y de Arqueología Medievales, V-VI, Cádiz. pp. $39 \mid-425$

MORA-FIGUEROA, L. de (1986): "Proyecto de un esquema básico para el estudio estructural, material y funcional de la arquitectura militar medieval". I Congreso de Arqueología Medieval Española, I. Zaragoza. pp. 437-442.

MORA-FIGUEROA, L. de (1990): "Arquitectura militar cristiana de la Edad Media española: estado de la cuestión". II Congreso de Arqueología Medieval Española, . Madrid. pp. 49-58.

MORA-FIGUEROA, L. de (1994): "Consideraciones sobre la bibliografía castellológica anglo-francesa". Estudio de Historia y Arqueología Medieval, Madrid. pp. 235-256.
MORILLA, J.P. (1992): "Proceso y formación del espacio territorial de Morón. Límites, organización y evolución". Desde la Frontera, 4. Morón de la Frontera. pp. 4I-83.

MORILLA, J.P. (1994): "Tierras, paisajes y líneas: usos y fronteras en el territorio moronés finimedieval". La Banda Morisca durante los siglos XIII, XIV y XV. Morón de la Frontera. pp. |19-147.

OLMO, L. (|99|): "Ideología y arqueología: Los estudios sobre el período visigodo en la primera mitad del siglo XX". Historiografía de la arqueología y de la Historia Antigua de España (siglos XVIII-XX). Madrid. pp. I57-I60.

ORIA, M. et alii (1990): El poblamiento antiguo en la Sierra Sur: Zona de Montellano. Sevilla.

ORTELIUS, A. (I596): Thesaurus geographicus. In quo omnium totius terrae regionum, montium...urbium...Oceani, marium...fluuviorum...lacuum, paludumque nomina et appellationes ueteres, additis magna ex parte etiam recentioribus...recognitus et auctus. Amberes.

PASCUAL, J. (1993): "El nombre latino y el origen de la ciudad de Morón". Desde la frontera, 6. Morón de la Frontera. pp. I-24.

PLATA Y NIETO, J. (19|4): "Nuestro propósito". Revista de Morón, I, Morón de la Frontera. pp. I-3.

PONSICH, M. (1973): Implatation rurale antique sur le Bas Guadalquivir: Alcala del Rio, Lora del Rio, Sevilla, Carmona. Madrid-Paris.

ROJAS GABRIEL, M. (1985-86): "El castillo de Olvera. Provincia de Cádiz". Estudios de Historia y Arqueología Medieval, V-VI. Cádiz. pp. 427-450.

ROJAS GABRIEL, M. (1987): "La torre de Lopera, arquetipo de la "Banda Morisca" (Utrera, Sevilla) (I.P.C.E. /I.B.I./D.G.B.A.: ESE-I, I-T-079-EM-B3)". II Congreso de Arqueología Medieval Española, II. Madrid. pp. 263-27I.

RUIZ, M.Ma (1985): Carta arqueológica de la campiña seviIlana: Zona Sureste. I. Sevilla.

RUIZ DE ZUÑIGA (19|4): "Un artículo". Revista de Morón, I, Morón de la Frontera. pp. 9-1 I.

SAAVEDRA, E. (| 88I ): La Geografía de España de El Idrisi. Madrid.

SALVATIERRA, V. (1990): Cien años de arqueología medieval. Perspectivas desde la periferia: Jaén. Jaén.

SIMONET, F.J. ( 1897): Historia de los mozárabes de España. Madrid.

TORRES Y LEON, I. de (19|4): "Los ladrillos de ValDuan". Boletín de la Real Academia de la Historia, XXVIII. Madrid. pp.265-290.

VERA et alii (1998): "La Huerta del rey. El espacio y sus usos a través de la historia" Sevilla extramuros. Coord M. Valor y C. Romero. Sevilla. pp. I05-| 48. 


\section{RESUMEN}

El artículo ofrece un análisis crítico de las principales investigaciones que, en los últimos siglos, se han producido en el campo de la arqueología medieval en la comarca sur de Sevilla. A la vez se establece una lectura comparativa con las corrientes más importantes que en este mismo ámbito se estaban desarrollando en la Península Ibérica.

\section{PALABRAS CLAVES:}

Historia de las investigaciones, visigodos, al-Andalus, Banda Morisca, Sevilla, Morón de la Frontera.

\section{ABSTRACT}

The paper contains a critical survey of the main research works in medieval archeology carried out in the southern region of Seville during the last centuries. These works are also compared with those ones carried out in the same period throughout the lberian Peninsula.

\section{KEY WORDS:}

History of investigations, Visigothic, al-Andalus, Morisco Border, Seville, Morón de la Frontera.

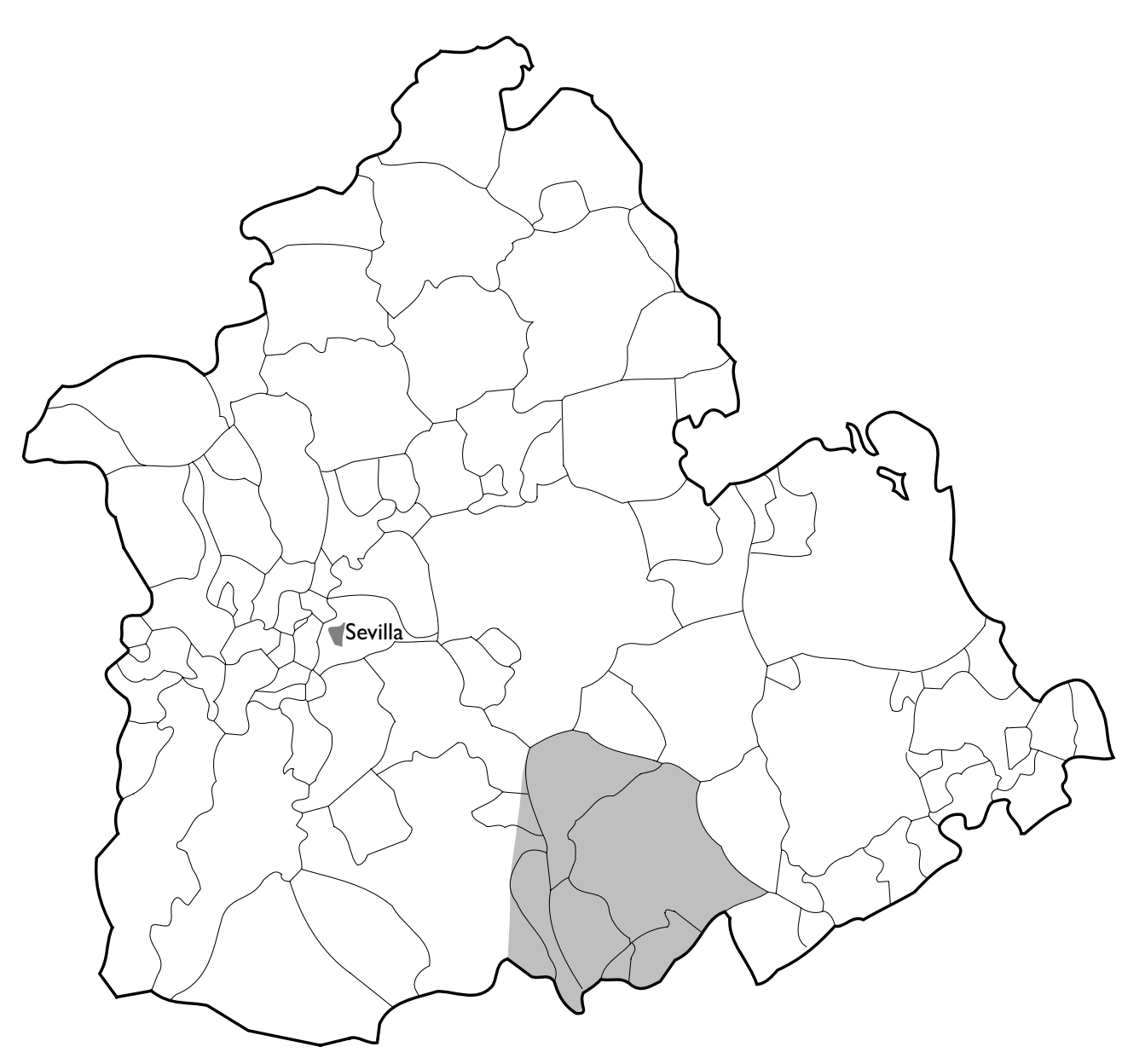

Fig. I. Plano de la provincia de Sevilla con indicación del área que abarca nuestro estudio 